\title{
Systems Learning Within the Context of Subject Learning
}

\section{Dr. Carrie Steinlicht, South Dakota State University}

Dr. Carrie Steinlicht is an Assistant Professor of Operations Management in the Department of Construction and Operations Management at South Dakota State University. She teaches Quality, Strategy, Cost Analysis, and Operations Mgt. subjects. She is currently researching process management systems in organizational contexts.

\section{Prof. Byron G. Garry, South Dakota State University}

Byron Garry is an Associate Professor and Undergraduate Program Coordinator in the Department of Construction \& Operations Management in the College of Engineering at South Dakota State University. 


\section{Systems Learning Within the Context of Subject Learning}

Introduction

Connecting curriculum to practice is one of the more difficult things to do in education and training. In manufacturing practice we must consider many aspects to a problem; whereas in education we often explore one topic at a time. Interdependence of the topics, however, is often more important than the topics themselves. Engineering practice requires a systems orientation. ${ }^{1}$

In a recent survey of industry needs, researchers conclude that systems thinking is one of the most important characteristics sought in university graduates hired by manufacturing firms. ${ }^{2}$ Systems thinkers are adept at understanding dynamic interdependence. ${ }^{3}$ Manufacturing processes are linked and intertwined and changes in one part of a system have effects and consequences that cascade through the entire system. As one factor changes, there are interactions across the system the leads to dynamic complexity.

In order to facilitate the development of systems thinking in students, educational practice must include activities that allow students to explore system dynamics and develop skills in the assessment of dynamic complexity. Traditional teaching methods that emphasize exploring individual topics seldom help in the development of critical thinking skills essential in systems thinking. Individual instructors face traditional faculty resistance to major curricular changes that incorporate systems thinking. But, the authors suggest that incorporating inductive teaching methods within the context of single topic courses is effective for developing systems thinking skills.

This study examines the use of a series of problem-based learning exercises within the context of a single topic course, specifically manufacturing cost analysis, which requires students to consider multiple subjects in order to solve a problem. The course exercises are broken down into nine steps, incorporating such steps as reverse engineering, computing materials costs, and drawing up a manufacturing plan, including tooling and labor costs. While doing these learning exercises, the students are developing a systems view of the problem. By incorporating systems thinking exercises in several courses, students will be better prepared to meet the needs of future employers.

\section{Active Learning and Problem-Based Learning}

Hattie, writing in "Visible Learning, A Synthesis of over 800 Meta-Analyses Related to Achievement", states "what teachers do matters". ${ }^{4}$ The way that professionals approach their craft of teaching has a large effect on whether students learn, or not. Good teachers provide “multiple opportunities and alternatives for developing learning strategies". 4

Hattie also states that "it is what learners do that matters." Passive learning through lectures, which is still happening in the majority of engineering classrooms, is not the best way to learn systems thinking. “...the aim is to make students active in their learning process - through actions by teachers and others - until the students reach the stage where they become their own 
teachers, they can seek out optimal ways to learn new material and ideas, they can seek resources to help them in this learning, and they can set appropriate and more challenging goals". 4

Active learning is generally defined as any instructional method that engages students in the learning process. Active learning requires students to do meaningful learning activities and think about what they are doing, particularly in the classroom. ${ }^{5}$ The 'constructivist' theory of learning, that existing knowledge is used to build new knowledge, is based on the student being an active learner. ${ }^{6}$ Felder, et al., found in a review of literature that when the objective of learning is to facilitate long-term retention of information, or to help the students develop or improve their problem-solving or thinking skills, instruction that involves students actively has consistently been found more effective than straight lecturing. ${ }^{7}$

Experiential learning, or problem-based learning (PBL), is defined as when a problem to be solved is defined before all the relevant information is provided. ${ }^{8}$ The process of solving the problem guides what the students learn. Prince ${ }^{8}$ found from his review of educational literature that active learning has benefits for student learning, but the assessment of those benefits is not always measureable and clearly defined. Some of the relevant benefits, such as students becoming more self-directed learners, are hard to measure. Other good student learning outcomes, such as measures of factual knowledge gained, can be affected by other factors outside of the active learning used in the classroom. Jamieson and Lohmann's 2012 ASEE report "Innovation with Impact - Creating a Culture for Scholarly and Systematic Innovation in Engineering Education” makes several recommendations for improving engineering education. Number 5 is to "Raise awareness of the proven principles and effective practices of teaching, learning, and educational innovation, and raise awareness of the scholarship of engineering education". ${ }^{9}$ There has been much study over the years on active learning and there is a "substantive body of knowledge of proven principles and effective practices in teaching, learning, and educational innovation." 9

The approach to a manufacturing cost analysis course could be the same as most engineering and technology education courses are taught, using a deductive approach. With the deductive approach, the instructor presents relevant theory and mathematical models, then moves on to textbook exercises, and then, in the case of best teaching practice, to real-world applications. Instructors often pursue what might be called the "Trust Me" approach to education, as in "Trust me-what I'm teaching you may seem pointless now but in another year or perhaps in four years you'll see why you needed it". ${ }^{7}$ A better way to motivate students, especially for this course, is through a specific inductive approach, problem-based learning. Here the instructor begins by presenting students with a specific challenge, a complex real-world problem to solve, and then the instructor lets the students move through the problem in a variety of different ways to find out how to solve the challenge that is posed. ${ }^{10}$ Students tend to study hardest and learn best when they are interested in and believe they have a need to know. Studies have shown that relative to students taught in the traditional deductive style, cooperatively taught students tend to have better and longer information retention, higher grades, more highly developed critical thinking and problem-solving skills, more positive attitudes toward the subject and greater motivation to learn it, better interpersonal and communication skills, higher self-esteem, and lower levels of anxiety about academics. ${ }^{7}$ 
Prince and Felder break down the various ways to use inductive teaching into one of six different types. ${ }^{10}$ Two different types of inductive teaching are found in the Manufacturing Cost Analysis course. The course uses aspects of both project-based and problem-based learning. Project-based learning involves assignments that call for students to produce something, such as a process or product design. The culmination of the project is normally a written or oral report summarizing what was done and what the outcome was. Dym, et al. say that project-based learning has produced many innovations in design pedagogy in engineering education. ${ }^{11}$ Research suggests that these kinds of courses appear to improve retention, student satisfaction, diversity, and student learning. In problem-based learning, students, usually working in teams, are confronted with an ill-structured open ended real-world problem to solve, and take the lead in defining the problem precisely, figuring out what they know and what they need to determine, and how to proceed to determine it. They formulate and evaluate alternative solutions, select the best one, make a case for it, and evaluate lessons learned. The authors see this manufacturing cost estimate course, although it based on a project, as presenting mostly problem-based learning as the students step through each part of the project.

The manufacturing cost estimate project was adapted from a similar project discovered at another institution long since forgotten. This project starts with a commercially produced coffee maker. The coffee maker is an ideal product for this exercise because it doesn't require the student to figure out how the product works. The mechanisms involved with heating the water are very simple and do not distract from the real purpose of the exercise, understanding what is involved with analyzing the costs involved in creating the product. In the course of the project, the coffeemaker is disassembled, analyzed, and reassembled. This type of learning activity has been used extensively in Engineering Curricula and has been labeled a Disassemble / Assemble / Analyze (DAA) activity. ${ }^{12}$ Within industry, a key purpose of DAA activities is to promote new and better design ideas. ${ }^{13}$

This manufacturing cost analysis project can also been seen through the lens of a Kolb Cycle process. ${ }^{14}$ The Kolb Cycle is defined as a cycle of concrete experience, reflective observation, abstract conceptualism and active experimentation. ${ }^{15}$

\section{Systems Thinking Definitions}

Wasson states that in general, engineers spend four years obtaining an engineering degree that may have an industrial "hands-on" life span of five to ten years, which is approximately $25 \%$ of an average career. ${ }^{16}$ At that point, they become team leaders, systems engineers, managers, et al., which place more emphasis on system engineering leadership, acquisition, and, management skills. They continue to build on their foundational domain engineering discipline knowledge and experience throughout their careers. However, anecdotal evidence and estimates suggest they spend from $50 \%$ to $75 \%$ of their total career-hours, on average, collaborating with others concerning the engineering of systems ... for which they may have no formal education or training.

Richmond proposes that system thinking is made up of seven critical thinking skills, which can be taught to students, so they can use them as separate tracks as a problem is approached. ${ }^{3}$ They are: 
- dynamic thinking, the ability to see and deduce behavior patterns rather than focusing on, and seeking to predict, events

- closed-loop thinking, when people think in closed loops, they see the world as a set of ongoing, interdependent processes rather than a laundry list of one-way relationships

- generic thinking, thinking generically, rather than specifically, seeing the underlying feedback loop that generates predator-prey, manic-depressive swing, etc.

- structural thinking, thinking in terms of units of measure or dimensions. Physical conservation laws must be adhered to. A conveyor belt line filling liquids needs to be seen as 2 separate measures - liters of fluid and bottle filled.

- operational thinking, thinking about how things really work, to ground students in reality

- continuum thinking, working with simulation models that have been built using a continuous, as opposed to discrete, approach

- scientific thinking, too often, science is taken to be synonymous with "measuring precisely". The ideal is to have the ability to put a scale (0-100) on things that are hard to quantify, and then to be able to think rigorously about the dynamics of the variable. Scientific thinking also means being rigorous about testing hypotheses.

Many definitions of systems thinking have been proposed, as summarized here. Rehmann sees system thinking as viewing a problem broadly and holistically; identifying interdependence and feedback; synthesizing as well as analyzing individual components; and accounting for dynamic (i.e., time-varying), nonlinear behavior. ${ }^{17}$ Frank and Waks say important considerations include understanding synergy, understanding implications of modifying the system, and solving systems failures are also important traits for systems engineers. ${ }^{18}$ Davidz found in, a survey of working system engineers, the importance of experiential learning. ${ }^{19}$ Based on a qualitative analysis of interviews, they found that thinking broadly, curiosity, questioning, being open-minded, communication, a tolerance for uncertainty, strong interpersonal skills and thinking out-of-thebox were all identified as important traits for successful system thinkers.

Froyd, et al. report from various sources that system thinking can include topics as diverse as system dynamics, which includes ideas such as feedback, time delay, difference equations, and differential equations; complexity theory, which variously includes self-organizing systems, highly organized tolerance, chaos, and complex adaptive systems; and project management, which includes capabilities for planning, scheduling, monitoring, and constructively intervening across a set of numerous interacting activities to realize a stated goal at a predetermined time. ${ }^{20}$

Senge refers to system thinking as a "body of knowledge and tools" that helps people see underlying patterns and how they can be changed. ${ }^{21}$ Froyd also reports on systems thinking and its connection with interdisciplinary thinking. ${ }^{20}$ Systems thinkers need to be able to integrate ideas, concepts, knowledge, and evidence across disciplinary boundaries. Dym, et al., say that engineering system design needs to incorporate thinking about system dynamics, reasoning about uncertainty, making estimates, and conducting experiments. ${ }^{22}$ Wasson says systems engineering embodies more than a top-down approach, which is only one aspect. ${ }^{16}$ As a problem solving / solution development and decision making methodology, it is a highly iterative, multi-faceted approach - i.e., top-down, bottom-up, left-right, right-left, etc. 
The CDIO Initiative "is based on a commonly shared premise that engineering graduates should be able to: Conceive - Design - Implement - Operate complex value-added engineering systems in a modern team-based engineering environment to create systems and products." ${ }^{23}$ Its goals, as applied to system thinking, are that students should be able to think holistically, think about emergence and interaction in systems, be able to use prioritization and focus, and be able to execute tradeoffs, judgment, and balance in resolution.

Sweeney and Sterman state that most advocates of systems thinking agree that much of the art of systems thinking involves the ability to represent and assess dynamic complexity (e.g., behavior that arises from the interaction of a system's agents over time), both textually and graphically. ${ }^{24}$

Sweeney and Sterman also state that specific systems thinking skills include the ability to:

- understand how the behavior of a system arises from the interaction of its agents over time (i.e., dynamic complexity)

- discover and represent feedback processes (both positive and negative) hypothesized to underlie observed patterns of system behavior

- identify stock and flow relationships;

- recognize delays and understand their impact;

- identify nonlinearities;

- recognize and challenge the boundaries of mental (and formal) models. ${ }^{24}$

Effective systems thinking also requires good scientific reasoning skills such as the ability to use a wide range of qualitative and quantitative data, and familiarity with domain-specific knowledge of the systems under study. ${ }^{24}$

\section{Classroom Examples of Systems Teaching}

Reported in engineering education literature recently are some examples of Systems Thinking teaching. At the most direct level of teaching system thinking, using the direct tools of the Systems Engineering community, an example is reported by Rehmenn, et al., at Iowa State University, who are teaching a limited-enrollment freshman/sophomore seminar. ${ }^{17}$ They introduce systems thinking using rich pictures ${ }^{25}$, casual loop diagrams and behavior-over-time graphs to approach a grand engineering challenge, as defined by the National Academy of Engineering.

Another is reported by Dunn, et al. at the MIT-Portugal Program, using a framework entitled CLIOS (Complex, Large-Scale, Interconnected, Open, Socio-technical) process by students concentrating on designing a high-speed rail system in Portugal. ${ }^{26}$ Another is reported by Wigal and Whitt at the University of Tennessee-Chattanooga, whose goal is to get freshmen to think systemically or holistically about problem solving, using Rich Pictures and the Integrated Definition model (IDEF0). ${ }^{27}$ Clelow, et al. at MIT report on their Introduction to Engineering Systems course, which uses and team-based projects and several novel systems analysis techniques to introduce the topic of engineering systems. ${ }^{28}$

Pierrakos, et al. at James Madison University teach a series of six design courses using problembased learning (PBL) experiences that reiterate the design process and expose students to design 
theory and practice, qualitative and quantitative reasoning, sustainability, systems thinking, ethics, and professional skills. ${ }^{29}$

Gandhi, et al. at the Stevens Institute of Technology propose that the use of case studies can be valuable in engineering education. ${ }^{30}$ They propose using systems thinking techniques, such as strategic assumption surface testing, soft systems methodology, critical thinking heuristics, postmodern systems thinking, and total systems intervention, will broaden the education of engineers.

An example of system thinking being taught in a course, but not using the direct tools of the Systems Engineering community, is reported by Aung at Lamar University in a Capstone course. ${ }^{1}$ They describe the process of integrating system thinking, reasoning, and decisionmaking skills into a Capstone-type course.

\section{Systems Thinking for Operations Professionals}

Manufacturing operations are systems that are emphatically interdisciplinary. Manufacturing operations bring together a wide variety of people, equipment, and processes that must work together to build products. They are highly complex adaptive systems that can change quickly. The nature of manufacturing is becoming less predictable as markets become more global. Static systems are not competitive; at least not for long. Workers change constantly and technology changes at a rapid rate. Operations are fluid and must be managed with this in mind.

It has become more important that operations professionals can view their workplace holistically and systematically for the best decision making. Students must be prepared to understand the broad impact of changes to one part of a system. It is necessary for students to understand that effects of changes are correlational, not causal. Factors are vast and interdependent and complex relationships between entities in the system are not entirely predictable. It is also important to be able to make decisions even though uncertainty exists. Not all factors are measurable or even known and sometimes decisions must be based upon probabilistic outcomes.

\section{Method of the project}

The Manufacturing Cost Analysis course, in the Manufacturing Engineering Technology (MNET) program at South Dakota State University, includes an inductive based project that seeks to enhance learning and promote systems thinking of students taking the course. The course is not considered a capstone course but rather a course designed to present topics of manufacturing cost estimating and engineering economy to senior level students. While the primary goal of the course is cost analysis, the instructor recognizes the importance of systems thinking and uses problem based learning methods to build student systems thinking skills.

The project begins with this problem statement:

One of the most important aspects of consumer product design is manufacturing cost. Because of stiff competition, manufacturers have little control over the selling price of their products. With many products (coffee makers and MP3 
players are examples) there is little or no performance difference between designs.

There are only two options to make more profit:

- Add features to justify a rise in price.

- Reduce manufacturing costs.

This assignment will study some of the factors that determine manufacturing costs in a simple product, the electric coffee maker. ${ }^{31}$

A good example of how to begin an inductive-based project is to start by posting an open-ended problem. In an inductive-based project there is no initial lecture on the problem. For the cost analysis problem, there was only a problem statement. There were no examples given to the students prior to the assignment and there were no worked problems. There is some structure imposed on the problem, by giving the students an outline of nine parts that they will follow, with each part due in roughly one-week intervals. The nine parts are:

1. Gather all necessary information

2. Analyze the make or buy decision

3. Generate a preliminary manufacturing plan

4. Compute direct materials cost

5. Compute tooling costs

6. Determine manufacturing operation time

7. Determine labor costs and burden rate

8. Comparison of coffee makers, and

9. Generate oral and written reports

First, the students are put into appropriately sized groups, usually two to three students. Each group is given a coffeemaker, and they decide amongst themselves, collaboratively, how they will attack the problem. Students are typically reluctant to participate in team based activities at the start. Experience shows that there is usually some resistance at the beginning of the project. This is a typical response as reported by Prince and Felder. ${ }^{10}$ However, students do appreciate the ability to divide up some of the work as it is quite extensive and requires a lot of time. The coffeemakers are all different brands and models so that any collaboration between groups is a sharing of techniques and general information, not an easy way out of doing the work (cheating).

A common difficulty faced by students here is transferring knowledge and skills acquired in other projects and classes to this project, which is in a different subject. Yet the integration of subjects is inherent in the complex environments the student intends to work in after graduation. ${ }^{20}$ The ability to understand dynamic complexity is widely regarded as the primary outcome of systems thinking. ${ }^{24}$ The impact of changes in one part of a system on the entire system is vitally important to successful operations. As noted earlier, the interaction of system parts is very difficult to convey in conventional technical and engineering education.

Conventional education usually focuses upon one topic at a time. Many curricula are designed this way and are not easily changed because of deeply ingrained academic cultures. One way to promote systems thinking in this type of environment is to require students to utilize what they have learned elsewhere in the curriculum in the process of learning another topic. This required integration of topics in an inductive based project underscores the interaction between system agents; in this case, within a manufacturing system. 
An open ended problem statement that utilizes resources that are ill-defined (a commercially available coffee maker) introduces a great deal of uncertainty in the project. The design of these products is seldom the same year over year. Each student group is given a different brand and model of coffee maker which makes it difficult to collaborate across groups. Each coffee maker has different parts, different assembly methods, and different packaging. There is no one correct solution for the project. Each student group must make multiple decisions based upon their own impressions created during disassembly and assembly. Project grading is not based upon correct answers, only correct methods.

Systems thinkers must be able to deal with uncertainty and estimating in system design. ${ }^{11}$ One of the first things that the students do for this project is break down their coffee maker and determine experimentally the method of manufacture and the time it would take a worker to build the product with simple tools (Steps 1, 2 \& 3). Students also must consider delays in the process due to transporting product, fatigue, personnel issues, and unavoidable stoppages (Step 6). Students start in this process a bit uncomfortable with estimating based upon their own experiences with the coffee maker, but, get more comfortable as the project progresses. By the end of the project, the students have a thorough understanding of their system and are able to predict what would happen if variables are adjusted.

Understanding interdependence and feedback is also characteristic of systems thinking. ${ }^{17}$ In manufacturing, there are multiple inputs that must be considered in system configuration. In this project, students are asked to design a manufacturing system to produce coffee makers to meet a specific demand (Step 6). At this point in the project, students have already determined customer needs, built a Bill of Materials for their coffee maker, and determined the order of steps necessary to build the coffee maker. Volume and demand rate play an important role in cost estimating labor and material expenses. By incorporating demand rate, students begin to understand how process design decisions must change to meet market needs. Later in the project, students are asked to suggest changes to the coffee maker design and determine the effect of the changes on the overall cost of the coffee maker (Steps 8 \& 9). Changes in design for cost savings result in changes throughout the system. Changes require students to adjust manufacturing processes, change number of employees, and buy different materials. These changes illustrate the interconnected nature of the process variables.

Interdisciplinary thinking is also important in systems thinking. ${ }^{20}$ Design of the product line based upon the time estimates the students determined in previous steps of the project require them to call upon previous coursework for knowledge of manufacturing process design. Optimization of the manufacturing system by altering the employee numbers and number of shifts, reorganizing the manufacturing steps, using parallel processing, line balancing, and other strategies has a significant impact on the cost of the manufacturing system. By asking the students to design with a takt rate in mind, students are incorporating multiple system inputs from multiple manufacturing/operations disciplines. By changing one item, students see that the entire system is affected.

During the course of this project students are asked to approach the project using multiple learning styles. ${ }^{14}$ This gives the students an opportunity to stretch themselves from their 
preferred style of learning. The students often see that other members of the project group are better at different parts of the project, probably because it fits that student's style of learning better. This allows the students to see, in action, that others learn differently. Seeing how others learn differently is another valuable systems thinking skill, which they will need to be aware of and use, when they work in industry.

While not every system thinking skill can be incorporated in this particular project, many of them can be addressed and by placing similar projects in other courses, systems thinking skills can be developed further.

Assessment of Learning

As a part of the MNET program's ABET-TAC Accreditation assessment process, student learning is assessed during this cost-estimation procedure. Specifically, the program assesses how well students meet Criterion 3, Student Outcome d) Graduates of the program have an ability to apply creativity in the design of systems, components or processes appropriate to program objectives. ${ }^{32}$ Over the course of the last three academic years, students have averaged a rating of 9 out of 10 on their learning for this procedure, with $95 \%$ of students meeting the goal of a rating of 8 out of 10 . The project is evaluated using an extensive rubric covering assembly drawings and design specifications, assembly and flow diagrams, material cost computations, manufacturing time and labor cost analysis, comparison of manufacturability, improvements proposed, and summary and conclusion.

Typical comments about the cost-estimating procedure are:

- Students gain an appreciation of the tools for cost estimation,

- Students have a better understanding of process design, and

- Students enjoy the concept-integrating nature of the project.

\section{Conclusion}

In the MNET program's Manufacturing Cost Analysis course, the faculty has, over the years, developed a cost estimating procedure that challenges the students through an inductive learning process. The students are presented with a problem to solve, and they must use several types of learning as they work their way through the process, to reach a goal of cost estimating related to various manufacturing processes and products and developing budget proposals for analysis and evaluation of manufacturing capital expenditure. Our incorporation of system thinking skills into this course is an on-going process.

This project illustrates one way system thinking skills can be incorporated into a traditional single subject per course curriculum. Problem based learning has been cited as one important tool in the preparation of systems thinkers. ${ }^{19}$ Through projects such as this one, system thinking skills can be enhanced. In this particular project, students must learn to view a problem systematically and holistically, learn how to deal with uncertainty and estimating through scientific inquiry, understand interdependence and interaction of system components, understand how different interdisciplinary subjects fit together to complete a system, and using different learning perspectives to build a more holistic view of how others perceive the system. 
Can this type of learning be extended to other courses and training opportunities? The authors of this paper believe that the use of a variety of teaching approaches has the potential to enhance the learning and performance for a wider range of adult students. Teaching portions of systems thinking in the inductive learning style, that is, begin by presenting students with a specific challenge, and then let the students move through a variety of different ways to find out how to solve the challenge, requires more work for the faculty, but it helps students practice how to become independent learners and systems thinkers.

Bibliography

1. Aung, K.T., 2012. Integration of Systems Thinking, Engineering Reasoning, and Decision Making in Design of Thermal Systems Course. Proceedings of the 2012 ASEE Annual Conference \& Exposition, Austin, TX.

2. Fliedner, G. \& Mathieson, K.., 2009. Learning Lean: A Study of Industry Lean Needs. Journal of Education for Business. 84(4): 194-199.

3. Richmond, B., 1993. Systems Thinking: Critical Thinking Skills for the 1990s and Beyond. System Dynamics Review, 9(2):113-133.

4. Hattie, J., 2010. Visible Learning, A Synthesis of over 800 Meta-Analyses Related to Achievement. London and New York: Routledge.

5. Bonwell, C.C., \& Eison, J. A., 1991. Active Learning: Creating Excitement in the Classroom. ASHEERIC Higher Education Report No. 1, George Washington University: Washington, DC.

6. Bransford, Brown and Cocking, Editors., 2000. How People Learn. Washington DC. National Academy Press. p. 139-142.

7. Felder, R.M., Woods, D.R., Stice, J.E. \& Rugarcia, A., 2000. The Future of Engineering Education II. Teaching Methods that Work. Chemical Engineering Education 34(1): 26-39.

8. Prince, M., 2004. Does Active Learning Work? A Review of the Research. Journal of Engineering Education, 93(3), 223-231.

9. Jamieson, L.H. \& Lohmann, J.R., 2012. Innovation with Impact - Creating a Culture for Scholarly and Systematic Innovation in Engineering Education. Washington, DC: ASEE.

10. Prince, M \& Felder, R., 2007. The Many Faces of Inductive Teaching and Learning, Journal of College Science Teaching. 36(5): 14-20.

11. Dym, C.L., A.M. Agogino, O. Eris, D.D. Frey, \& L.J. Leifer, 2005. Engineering Design Thinking, Teaching, and Learning. Journal of Engineering Education 94(1):103-120.

12. Ogot, M. \& Kremer, G., 2006. Developing a Framework for Disassemble / Assemble / Analyze (DAA) Activities in Engineering Education. Proceedings of the 2006 ASEE Annual Conference \& Exposition, Chicago, IL.

13. Dalrymple, O.O., Sears, D.A., \& Evangelou, D., 2011. The Motivational and Transfer Potential of Disassemble / Assemble / Analyze Activities. Journal of Engineering Education, 100(4): 741-759.

14. Garry, B. \& Steinlicht, C., 2013. Inductive Learning Activities for Process Development and Cost Estimating. Journal of Management and Engineering Integration, Winter Issues, Vol. 5.

15. Kolb, D.A., \& Boyatzis, R.E., 2000. Experiential Learning Theory: Previous Research and New Directions. In R. J. Sternberg, \& L. F. Zhang (Eds.), Perspectives on Cognitive, Learning, and Thinking Styles. NJ, Lawrence Erlbaum.

16. Wasson, C.S., 2012. Systems Engineering Competency: The Missing Course in Engineering Education. Proceedings of the 2012 ASEE Annual Conference \& Exposition, Austin, TX

17. Rehmann, C. R., Rover, D.T., Laingen, M., Mickelson, S.K., \& Brumm, T.J., 2012. Introducing Systems Thinking to the Engineer of 2020. Proceedings of the 2012 ASEE Annual Conference \& Exposition, Austin, TX.

18. Frank, M., \& Waks, S., 2001. Engineering Systems Thinking: A Multifunctional Definition. Systemic Practice and Action Research 14(3): 361-379.

19. Davidz, H.L. \& Nightingale, D.L., 2008. Enabling Systems Thinking to Accelerate the Development of Senior System Engineers. Systems Engineering 11(1): 1-14. 
20. Froyd, J., Pchenitchnaia, L., Fowler, D. \& Simpson, D., 2007. Systems Thinking and Integrative Learning Outcomes. Proceedings of the 2007 ASEE Annual Conference \& Exposition, Honolulu, HI.

21. Senge, P. M., 1990. The Fifth Discipline: The Art and Practice of the Learning Organization. In Ott, J. S., Parkes, S. J., \& Simpson, R. B., 2003. Classic Readings in Organizational Behavior. (pp.484-491). Belmont, CA: Wadsworth/Thomson Learning.

22. Dym, C.L., 2004. Design Systems and Engineering Education. International Journal of Engineering Education 20(3): 305-312.

23. CDIO Initiative. CDIO: A New Vision for Engineering Education. Retrieved Nov. 1, 2012 from http://www.cdio.org/benefits-cdio

24. Sweeney, L.B. \& Sterman, J.D., 2000. Bathtub Dynamics: Initial Results of a Systems Thinking Inventory. System Dynamics Review, 16(4):249-286.

25. Checkland, P., \& J. Poulter., 2006. Learning for Action. New York: John Wiley \& Sons.

26. Dunn, T.P., Sussman, J.M., Stein, N.E.G., \& Uniman, D.L., 2012. Integrating Engineering Systems Research and Undergraduate Education through a Term-Length Case Study. Proceedings of the 2012 ASEE Annual Conference \& Exposition, Austin, TX.

27. Wigal, C. \& Whitt, J., 2010. Identifying and Defining Relationships: Techniques for Improving Student Systemic Thinking. Proceedings of the 2010 ASEE Annual Conference \& Exposition, Louisville, KY.

28. Clelow, R.R., Siddiqi, A., \& Sussman, J.M., 2012. Introducing Engineering Systems to First- and Second-Year Students through Project-Based Learning. Proceedings of the 2012 ASEE Annual Conference \& Exposition, Austin, TX.

29. Pierrakos, O.P., Pappas, E.C., Nagel, R.M., \& Nagel, J.K., 2012. A New Vision for Engineering Design Instruction: On the Innovative Six Course Design Sequence of James Madison University. Proceedings of the 2012 ASEE Annual Conference \& Exposition, Austin, TX.

30. Gandhi, S.J., Sauser, B., White, B.E., Gorod, A., \& Ireland, V., 2012. Application of Case Studies to Engineering Management and Systems Engineering. Proceedings of the 2012 ASEE Annual Conference \& Exposition, Austin, TX.

31. Steinlicht, C., 2012. MNET 460 Project Assignment. South Dakota State University.

32. ABET. 2011-12 Criteria for Accrediting Engineering Technology Programs. Accreditation Board for Engineering and Technology, Engineering Technology Accreditation Commission. Baltimore, MD. Retrieved Nov. 1, 2012 from www.abet.org 